\title{
Image Processing In Intelligent Traffic Management
}

\author{
Ishaan Gulati and R. Srinivasan
}

\begin{abstract}
Traffic monitoring and traffic control have always been challenging tasks. Intelligent Transportation Systems (ITS) based on wide range of technologies have certain practical challenges in their application and implementation. Video surveillance has proven advantageous over traditional systems based on inductive loops sensors and detectors for traffic monitoring. Accurate traffic density estimation which is basic to tackling traffic congestions requires detection of vehicles, assessing their speed, and tracking vehicles passing through surveillance zones. Image processing techniques require processing of large number of image frames for real-time applications in traffic management. More efficient and less costly image processing techniques for accurate vehicle detection and density determination are required for developing more effective traffic management systems. There is a need for developing algorithms with robust performance under heavy traffic loads and varied environmental conditions. Developments in artificial intelligence offer new vistas in image processing for regulation and management of traffic by signal control mechanisms and creation of neural networks for unhindered traffic flow.
\end{abstract}

Index Terms: Image processing techniques, Intelligent traffic management, Traffic monitoring, Vehicle detection

\section{INTRODUCTION}

Exponentially increasing vehicular traffic has led to many issues ranging from traffic congestions to increased incidence of road accidents. Traffic jams confronted in metropolitan cities hamper human routine and add to travel and transportation cost due to extra fuel burning by stranded vehicles at road intersections and highways. An intelligent traffic management and continuous surveillance for real-time monitoring of traffic are essential to seeking information-based intelligent solutions to streamline vehicular flow through reduced traffic congestion on roads [1], [2]. Accurate traffic density estimation is basic to tackling traffic congestions for improvisation of traffic management systems. This needs detection of moving vehicles, tracking of vehicles and estimation of their speeds through surveillance zones. Intelligent transportation systems (ITS) based on magnetic loop, infra-red radar, microwave RADAR, ultrasonic and video processing based sensors have been employed for traffic management [3].

Vision based ITS have been widely used in traffic regulation due to their proven advantages over traditional

Revised Manuscript Received on July 05, 2019.

Ishaan Gulati, Computer Science Engineering Department, SRM Institute of Technology \& Science, SRM Nagar, Kattankulathur, 603203

R. Srinivasan, Computer Science Engineering Department, SRM Institute of Technology \& Science, SRM Nagar, Kattankulathur, 603203 methods of traffic control [3], [4]. Image processing systems are based on motion detection of vehicles, wherein computer vision algorithms extract vehicles from traffic video data for traffic density estimations. Vision-based traffic control systems have common basic architect of vision acquisition and pre-processing for feature enhancement. Image processing techniques have been widely applied for collecting real-time traffic information about vehicle count and vehicular movement. However, more efficient and affordable image processing techniques based on robust algorithms are required for accurate vehicle density determination under conditions of varying day-night illuminations and heavy traffic load for providing more detailed and complete information for traffic engineering [5]. Thus, more efficient and less costly image processing techniques based on vehicle tracking algorithms with effective performance are required for accurate vehicle density determination. More recently, self-learning algorithms are being developed to provide efficient and cost effective approaches in solving various vehicular problems to decrease traffic load across various routes and road-networks. In this context, deep learning, machine learning and big data analytics solutions have been sought to make use of real-time traffic data for prediction of traffic density of entire map area to specifically suggest optional routes from source of destination and adaptive signaling for development of smart network traffic control systems [6], [7].

This paper briefly reviews various types of detectors in applications for generating information about traffic, developments in vision-based image processing techniques considered as reliable and economical for intelligent traffic regulation, and image processing based traffic monitoring conjoined to machine learning with wide prospects in traffic management.

\section{TYPES OF DETECTORS EMPLOYED FOR TRAFFIC DETECTION}

Automated traffic systems have employed various types of detectors and sensors for applications in vehicle detection, traffic surveillance, real-time traffic adaptive signal control, commercial and emergency information services [8]-[13], (Table I).

Ultrasonic, infrared, microwave RADAR and LASER based detector systems require structured traffic and lane discipline besides separate systems for vehicle count and traffic surveillance. Magnetic loop technology unlike 
LASER based and RADAR systems is intrusive resulting in road damage. Infrared sensors are more effected by fog than video cameras in their performance. In overall comparison, image processing techniques are more efficient and effective as these techniques generate more information about traffic, by combining surveillance and traffic control technologies and are non-intrusive, easy to

install and scalable. Accordingly, vision based ITS have attracted considerable attention for R\&D in the last two decades [3].

\section{DEVELOPMENTS IN IMAGE PROCESSING METHODS}

Image processing involves signal processing with photograph or video frame as input and image or characteristic parameters of image as output. An image is interpreted as two- dimensional signal by using standard signal-processing techniques [14], [15]. The binary digital data of image is used to extract relevant information after image enhancement, edge enhancement and brightening [16]. A common architect of traffic control incorporates image acquisition, preprocessing and density calculation [17].

Table I. Capabilities, strengths and weaknesses of various detector systems employed for vehicular traffic monitoring.

\begin{tabular}{|c|c|c|c|}
\hline Detector Type & Capability & Strengths & Weaknesses \\
\hline $\begin{array}{l}\text { Inductive } \\
\text { Loop }\end{array}$ & $\begin{array}{l}\text { Provides detection, } \\
\text { presence, occupancy } \\
\text { and count of vehicles }\end{array}$ & $\begin{array}{l}\text { Economical on unit cost } \\
\text { Mature, extensively used technology } \\
\text { Flexible design for large variety of applications } \\
\text { Performance not affected by harsh } \\
\text { environmental conditions of rain, fog and snow } \\
\text { Provides the highest accuracy for vehicle count } \\
\text { Commonly employed standard for accurate } \\
\text { occupancy measurements }\end{array}$ & $\begin{array}{l}\text { Traffic disruptions while installation and } \\
\text { maintenance } \\
\text { Prone to damage by heavy vehicular } \\
\text { movements and during road repairs }\end{array}$ \\
\hline $\begin{array}{l}\text { Microwave } \\
\text { RADAR }\end{array}$ & $\begin{array}{l}\text { Provides detection, } \\
\text { presence, occupancy, } \\
\text { speed, classification } \\
\text { and count of vehicles } \\
\text { Detection of } \\
\text { stationary vehicles } \\
\text { by frequency- } \\
\text { modulated } \\
\text { continuous wave } \\
\text { microwave RADAR }\end{array}$ & $\begin{array}{l}\text { Compact size } \\
\text { No traffic disruptions during installation and } \\
\text { road repairs } \\
\text { Direct measurement of vehicle speed } \\
\text { Provision for multilane function } \\
\text { Typically insensate to inclement weather }\end{array}$ & $\begin{array}{l}\text { Trouble shootings of overestimating speed } \\
\text { and occupancy values } \\
\text { CW Doppler sensors cannot detect stationary } \\
\text { vehicles }\end{array}$ \\
\hline LASER & $\begin{array}{l}\text { Provides presence, } \\
\text { counting, } \\
\text { classification and } \\
\text { speed of vehicles }\end{array}$ & $\begin{array}{l}\text { Installation does not need civil engineering } \\
\text { works on the road floor }\end{array}$ & $\begin{array}{l}\text { Application limited to structured traffic } \\
\text { Reduced performance during low visibility } \\
\text { and heavy rains } \\
\text { Costly }\end{array}$ \\
\hline Infrared & $\begin{array}{l}\text { Both active infrared } \\
\text { and passive infrared } \\
\text { detect presence and } \\
\text { passage of vehicles }\end{array}$ & $\begin{array}{l}\text { Day-night operation } \\
\text { Better performance than visible wavelength } \\
\text { sensors } \\
\text { Compact size }\end{array}$ & $\begin{array}{l}\text { No information about speed of vehicles } \\
\text { Thermal IR sensors have constraints } \\
\text { concerning operating temperatures } \\
\text { Only cool infrared detectors provide high } \\
\text { sensitivity } \\
\text { Reduced sensitivity under fog, rain and snow }\end{array}$ \\
\hline Ultrasonic & $\begin{array}{l}\text { Provides presence, } \\
\text { occupancy, speed, } \\
\text { and count of vehicles }\end{array}$ & $\begin{array}{l}\text { Multiple lane operation } \\
\text { Availability of experience base } \\
\text { Capable of detecting overweight vehicles }\end{array}$ & $\begin{array}{l}\text { Sensitive to noise } \\
\text { Difficulty in detecting snow covered vehicles } \\
\text { Attenuation and distortion by environmental } \\
\text { conditions -temperature, air turbulence and } \\
\text { humidity } \\
\text { Expensive }\end{array}$ \\
\hline Magnetometer & $\begin{array}{l}\text { Provides detection, } \\
\text { presence, occupancy } \\
\text { and count of vehicles }\end{array}$ & $\begin{array}{l}\text { Installed in bridge decks and concrete surfaces } \\
\text { like pavements unlike loop detectors }\end{array}$ & $\begin{array}{l}\text { Installation by boring or cut in pavements } \\
\text { Limited applications in detection of stationary } \\
\text { vehicles } \\
\text { Medium cost }\end{array}$ \\
\hline $\begin{array}{l}\text { Video image } \\
\text { processing }\end{array}$ & $\begin{array}{l}\text { Provides detection, } \\
\text { presence, } \\
\text { occupancy, speed, } \\
\text { classification and } \\
\text { count of vehicles }\end{array}$ & $\begin{array}{l}\text { Provides living image of real-time traffic status } \\
\text { Covers multi-lane and multiple detection zones } \\
\text { in a lane } \\
\text { Wide area detection on collation of information } \\
\text { generated from different cameras located at } \\
\text { different places } \\
\text { No traffic interruptions during installation and } \\
\text { repairs } \\
\text { Low installation and maintenance costs }\end{array}$ & $\begin{array}{l}\text { Costly equipment for transfer of real-time } \\
\text { video-image data } \\
\text { Separate algorithms required for day and night } \\
\text { traffic detections } \\
\text { Possibilities of discrepancies appearing } \\
\text { during traffic data transition } \\
\text { Performance prone to obscurants and heavy } \\
\text { atmospheric conditions. }\end{array}$ \\
\hline \multicolumn{4}{|c|}{$\begin{array}{l}\text { Background modeling is done } \\
\text { following image acquisition } \\
\text { and pre-processing for }\end{array}$} \\
\hline
\end{tabular}


efficient detection of moving objects.

Different background modeling techniques have been proposed: segmentation of dynamic scenes [18]; self-adaptive average of current background and new image [19]; sliding window concepts with frames in buffer for background modeling [20]; probability density function approach to generate good background image [21]; long-term average of image-capture to dynamically select useful set of features frame by frame in a time interval [22]; and multi-feature model using Online Robust Principal Component Analysis [OR-PCA) to build a robust low-rank background [23]. These approaches have commonly employed frame difference and background subtraction for detection of moving objects while frame differencing detects only leading and trailing edges of uniformly coloured objects. Similarly, labeling of only some pixels on the object makes difficult discerning its movement towards or away from the camera. Hadi et al. proposed an approach for moving vehicle detection based on background subtraction and morphological binary operations. Consequently, background subtraction has been used by feature extraction reducing voluminous data, matching of template image and contour salience techniques for identifying vehicles [23], [24], and mean shift algorithm and template matching algorithm for tracking moving vehicles [25], [26]. These approaches have issues of fake vehicle detection in background subtraction. However, vehicles feature detection and mean shift calculation introduce memory and time overhead to address issues of false-positive vehicle detection [27].

Notwithstanding considerable improvements in image processing techniques, available commercial software are dogged by problems of inability to detect and handle vehicle occlusions from camera view [28]-[30], limited functionality in severe weather conditions [31], [32], undesired factors like damaged road or white marks on the road surface and shadows of trees and buildings and nighttime vehicle detection [33], and overcrowded roads [34]. Another major drawback of video analytic algorithms is the lack of inter-system compatibility with already installed hardware, unless these two components are products of the same manufacturer. Open platforms like the Open Network Video Interface Forum [ONVIF) have been devised but their applications are not yet fully standardized as integration of products from different vendors remains at basic level [35].

\section{VEHICLE DETECTION AND CLASSIFICATION}

Overviews of state-of-art algorithms have been proposed for vehicle detection and classification [36], [37]. Trucks and heavy vehicles have been counted and classified according to their length using images from non-calibrated video cameras [38]. However, dynamic background subtraction method employed for counting numbers and length of vehicles moving in a straight line extracted at a particular point in the view does not work in heterogeneous traffic scenes. Likewise, the adaptive background subtraction have been used to detect moving vehicles using their bottom coordinates and tracking before counting and classifying them into small, medium and large classes of vehicles [39]. This approach for effective performance assumes that at any given point of time a vehicle will occupy only one lane. To eliminate complicated camera calibrations, un-calibrated video cameras have also been proposed for video-based vehicle detection and classification system for traffic data collection to achieve a balance between algorithm complexity and effectiveness for real-time applications [40]. But these approaches do not account for transient alterations in illumination in a scene [41]. Invariant moments and shadow aware foreground masks have also been used with computational efficiency to count and classify vehicles using perspective projection of scene geometry using Mixture of Gaussians model [42]. Similarly, cropping method has been used to minimize false positives in detecting, tracking and estimating speeds of moving vehicles by selecting the Region of Interest (ROI). Parameters like position, height and width of vehicle instead of features extraction have been applied with less computation and memory for detection and tracking of moving vehicles for easy adoption in traffic management system [27].

\section{VEHICLE COUNTING AND DENSITY ESTIMATION}

Motion detection in combination with vehicle detection have been applied in background subtraction technique for locational traffic density estimation [43]. Frame differencing technique is used for detection of vehicle motion. Histogram of the key region parts of two consecutive frames is analyzed and compared with the derived threshold. Difference of two 1-pixel wide profiles extracted by median filtering is applied to minimum 3-pixel-wide derived threshold profile of image for detection of motion. Difference between these profiles depicts displacement or motion of the object. However, the technique is constrained by requirement for at least 3-pixel wide profile of an image in key region along the road. The road image is divided into subparts, followed by the application of background subtraction technique for vehicle detection. In Canny edge detection method [44], an adaptive background subtraction is first done and then the method is applied for edge detection of vehicle while considering all neighborhood pixels for detecting edges of all vehicles present in the image. Moore neighborhood algorithm with Jacob's criterion has been found superior to static background subtraction technique for object detection. Kanungo et al. [45] proposed to calculate real time traffic density based on live video feed where traffic density is factored in decision making process for regulating traffic lights without additional hardware.

A comparative account of various methods employed for vehicle count/density calculation is presented in Table II.

Table II. Algorithms of various image processing techniques used for vehicle count/traffic density estimations

Blue Eyes Intelligence Engineering 


\begin{tabular}{|c|c|c|c|}
\hline Technique & $\begin{array}{c}\text { Image } \\
\text { Acquisition }\end{array}$ & $\begin{array}{c}\text { Image } \\
\text { Processing }\end{array}$ & Density Calculation \\
\hline $\begin{array}{l}\text { Background } \\
\text { Subtraction }\end{array}$ & $\begin{array}{l}\text { Camera } \\
\text { based } \\
\text { systems }\end{array}$ & $\begin{array}{c}\text { Grayscale } \\
\text { conversion } \\
\text { Conversion to } \\
\text { binary pattern } \\
\text { Erosion } \\
\text { Dilation } \\
\end{array}$ & $\begin{array}{l}\text { Motion detection by } \\
\text { analysis of two } \\
\text { consecutive frames } \\
\text { employing constant } \\
\text { background frame and } \\
\text { current frame. }\end{array}$ \\
\hline $\begin{array}{c}\text { Edge } \\
\text { Detection }\end{array}$ & $\begin{array}{l}\text { Camera } \\
\text { based } \\
\text { systems }\end{array}$ & $\begin{array}{c}\text { Image } \\
\text { conversion to } \\
\text { grayscale } \\
\text { Background } \\
\text { subtraction }\end{array}$ & $\begin{array}{l}\text { Vehicle edge detection } \\
\text { by Canny edge } \\
\text { detection algorithm } \\
\text { Object count by } \\
\text { Moore neighborhood } \\
\text { algorithm }\end{array}$ \\
\hline $\begin{array}{l}\text { Algorithm } \\
\text { proposed by } \\
\text { Kanungo et } \\
\text { al. [45] }\end{array}$ & $\begin{array}{l}\text { Camera } \\
\text { based } \\
\text { systems }\end{array}$ & $\begin{array}{l}\text { Grayscale } \\
\text { conversion }\end{array}$ & $\begin{array}{c}\text { Vehicle density } \\
\text { calculation algorithm } \\
\text { and formula proposed } \\
\text { by Kanungo et al. }\end{array}$ \\
\hline Dual Method & $\begin{array}{l}\text { Camera } \\
\text { based } \\
\text { systems }\end{array}$ & $\begin{array}{c}\text { Image } \\
\text { conversion to } \\
\text { grayscale }\end{array}$ & $\begin{array}{l}\text { Vehicles detection by } \\
\text { gradient magnitude } \\
\text { and direct subtraction } \\
\text { techniques }\end{array}$ \\
\hline $\begin{array}{l}\text { Gradient } \\
\text { Method }\end{array}$ & $\begin{array}{l}\text { Camera } \\
\text { based } \\
\text { systems }\end{array}$ & $\begin{array}{l}\text { Image } \\
\text { conversion to } \\
\text { grayscale } \\
\text { Gamma } \\
\text { correction } \\
\end{array}$ & $\begin{array}{l}\text { Using Canny edge } \\
\text { detector and gradient } \\
\text { based edge detection }\end{array}$ \\
\hline
\end{tabular}

Various algorithms using image processing techniques to estimate traffic density extend certain advantages and limitations (Table III).

\section{Table III. Advantages and disadvantages of algorithms used in image processing techniques for vehicle count/density calculation}

\begin{tabular}{|c|c|c|}
\hline Technique & Advantages & Limitations \\
\hline $\begin{array}{c}\text { Backgroun } \\
\mathrm{d} \\
\text { Subtraction } \\
\text { Technique }\end{array}$ & $\begin{array}{l}\text { Reasonably priced } \\
\text { Scalable }\end{array}$ & $\begin{array}{l}\text { Lacks robustness to } \\
\text { occlusion } \\
\text { Static background } \\
\text { insufficient to deal with } \\
\text { change in outdoor } \\
\text { environments }\end{array}$ \\
\hline $\begin{array}{c}\text { Edge } \\
\text { Detection } \\
\text { Technique }\end{array}$ & $\begin{array}{l}\text { Cost effective } \\
\text { Scalability } \\
\text { Smoothing effect to reduce } \\
\text { background noise } \\
\text { Improved vehicle detection } \\
\text { efficiency } \\
\text { Reduced data storage and } \\
\text { transmission time }\end{array}$ & $\begin{array}{l}\text { Lacks robustness to } \\
\text { occlusion } \\
\text { Time consuming } \\
\text { Sensitivity to } \\
\text { environmental variations }\end{array}$ \\
\hline $\begin{array}{l}\text { Algorithm } \\
\text { proposed } \\
\text { by } \\
\text { Kanungo et } \\
\text { al. [45] }\end{array}$ & $\begin{array}{l}\text { Relatively low installation } \\
\text { and maintenance } \\
\text { expenditure } \\
\text { Enhanced effectiveness for } \\
\text { reducing congestion and } \\
\text { waiting period }\end{array}$ & $\begin{array}{l}\text { Sensitive to low light } \\
\text { conditions like overcast } \\
\text { sky and after }\end{array}$ \\
\hline $\begin{array}{l}\text { Dual } \\
\text { Method } \\
\text { Technique }\end{array}$ & $\begin{array}{l}\text { Relatively low installation } \\
\text { expenditure } \\
\text { Provides for occlusion } \\
\text { situations }\end{array}$ & $\begin{array}{l}\text { Complex method } \\
\text { Reduced performance } \\
\text { under low light }\end{array}$ \\
\hline $\begin{array}{l}\text { Gradient } \\
\text { Method }\end{array}$ & $\begin{array}{l}\text { Reasonably priced } \\
\text { Simple technique } \\
\text { Efficient based on Canny } \\
\text { edge detector }\end{array}$ & $\begin{array}{l}\text { Limitations for night } \\
\text { applications } \\
\text { Deficit efficiency in image } \\
\text { matching for vehicle } \\
\text { count }\end{array}$ \\
\hline
\end{tabular}

Techniques employed for road traffic density analysis mainly rely on motion detection or background modeling and subtraction to detect vehicles [10], thus limited by their application only to free-flowing traffic scenes or scenes with static backgrounds. Also segmentation results when used with traditional static background subtraction method were not reliable since changing illumination conditions were not factored [46]. Therefore, dynamic background modeling offered advantage of handling changing scene conditions [45, 46], though this method could not be used for stationary traffic monitoring. In fact, many proposed approaches for traffic monitoring have not been tested for performance under dissimilar illumination conditions. Employing Approximated Median Filter technique, which detects pixels corresponding to moving objects, sufficient accuracy and reliability was obtained in real-time vehicle counting in challenging situations of low-resolution videos, rainy scenes and situations of stop-and-go traffic [47]. Vehicle detection is tough task in tunnels owing to poor illumination, reflected light and low resolution in videos. Background subtraction and Deep Belief Network [DBN) with three-hidden layer architecture was introduced for vehicle detection in tunnels [48]. Nellore et al found Euclidean distance superior to Manhattan distance and Canberra distance techniques in vision based sensing and time sensitive alert transmission within the sensor network for prioritizing movement of emergency vehicles such as ambulances, police cars and fire engines at road intersections [49]. Computer vision-guided adaptive signal timing Throughput and Average Waiting Time Optimization [TAWTO) algorithm based on cluster counts of approach roads was proposed for entry and exit of intersection approaches for improved average waiting time and throughput for traffic movement [50].

The machine-learning techniques can play a major role in improving existing traffic controls as self-learning algorithms to provide an effective and cost-efficient approach in solving various vehicular problems to decrease the load on traffic across the route. The traditional signal systems do not have the ability to customize duration of green signal according to the traffic scene and decide which lane needs more duration of green signal on the basis of number or density of vehicles in various lanes. The machine learning solutions have been employed to provide predictive analysis of traffic in a given area using supervised learning techniques to predict the traffic densities of entire map area as per real-time traffic data to obtain a bigger picture to reduce congestion of traffic on all roads the city. The Distributed Reinforcement Learning techniques have been used to overcome some disadvantages of centralized synchronization of traffic control methods in decision making for real-time control and guidance of traffic. Thus machine learning techniques can provide dynamic guidance and control solutions in improving the existing traffic-control technologies for smart traffic control management.

\section{CONCLUSIONS AND FUTURE PROSPECTS}

A continuous improvement in automated traffic systems is imperative to deal with traffic 
jams which have become a serious problem due to escalating add up of vehicles in big cities. Vision-based systems have proven more effective over other systems in traffic management. However, most of these systems tend to break down under heavy traffic density due to occlusion heavy traffic loads and various algorithms need to be tested under varying illuminations of day and night under low, medium and heavy traffics. Thus, development of more efficient adaptive systems with multiple cameras installed at road intersections and roadsides is essential to regulating timings of traffic lights, analyzing traffic build up from start-point to end-point besides localized congestions, and synchronizing multiple traffic lights aimed at mitigating traffic congestions for free traffic flow over large areas. Development of algorithms for image processing techniques for identification of emergency vehicles for prioritizing their movement can also help eliminate requirements of additional hardware such as siren based sensors and radio-frequency identification tags. Further advancements in video based traffic-flow detection can help in developing increasingly robust, real time and intelligent traffic management in optimized system structure. There is enormous scope of image processing in traffic monitoring and analysis for the future technologies. The biggest challenge lies in integrating multitude technical specialties into a unified approach with accuracy to achieve fail-safe dependability of traffic management systems.

\section{ACKNOWLEDGMENT}

Authors acknowledge Director, SRM Institute of Engineering and Science, Kattankulathur, India and Head, Computer Science Engineering Department, SRM Institute of Engineering and Science, Kattankulathur, India for their encouragement and support.

\section{REFERENCES}

1. M.Bernas, B. Płaczek, W. Korski, P. Loska, J. Smyła, P. Szymała. (2018, October). A survey and comparison of low-cost sensing technologies for road traffic monitoring. Sensors, [Online] 18(10). pp. 3243-3270. Available: https://doi.org/:10.3390/s18103243

2. V. Ukani, S. Garg, C. Patel, H. Tank. (2016, November). Efficient vehicle detection and classification for traffic surveillance system. Communications in Computer and Information Science (CCIS), [Online]. pp. 495-503.Available: https://doi.org/:10.1007/978-981-10-5427-3_51

3. N.K. Jain, R.K. Saini, and P. Mittal, "A Review on Traffic Monitoring System Techniques", Soft Computing: Theories and Applications. Advances in Intelligent Systems and Computing, Springer, 2019. [Online], pp. 569-577, Available: https://doi.org/10.1007/978-981-13-0589-4

4. Md. R. Islam, N.I. Shahid, D.T. ul Karim, A.A. Mamun, Md.K. Rhaman, "An Efficient Algorithm for Detecting Traffic Congestion and a Framework for Smart Traffic Control System", 18th International Conference on Advanced Communication Technology (ICACT), Pyeong Chang and Busan Gwang'yeogsi, South Korea March 2016. [Online] Available https://doi.org/: 10.1109/ICACT.2016.7423566

5. Z.Yang, L.S.C. Pun-Cheng (2018, January). Vehicle detection in intelligent transportation systems and its applications under varying environments: A review. Image. Vis. Comput. [Online] 69, pp. 143-154, Available: https://doi.org/: 10.1016/j.imavis.2017.09.008.

6. Z. Md. Fadlullah, F. Tang, B. Mao, N. Kato, O. Akashi, T. Inoue, K. Mizutani. (2017, May). State-of-the-art deep learning: evolving which calls for developing robust algorithms to deal with

machine intelligence toward tomorrow's intelligent network traffic control systems. IEEE Commun. Surv. Tutor. [Online]. 17(4), pp. 2432-2455, 2017. Available:

https://doi.org/:10.1109/COMST.2017.2707140

7. A. Sharif, J. Li, M. Khalil, R. Kumar, M.I. Sharif, A. Sharif, (2017, December). "Internet of things-smart traffic management system for smart cities using big data analytics," 14th International Computer Conference on Wavelet Active Media Technology and Information Processing (ICCWAMTIP), [Online].pp 281-284. Available: https://doi.org/: 10.1109/ICCWAMTIP.2017.8301496

8. M. Bommes, A. Fazekas, T. Volkenhoff, M. Oeser.(2016, June). Video based intelligent transportation systems - State of the art and future development. Transp. Res. Procedia, [Online] 14, pp. 4495-4504 Available:

https://doi.org/: 10.1016/j.trpro.2016.05.372

9. Md. R. Islam, N.I. Shahid, D.T. ul Karim, A.A. Mamun, Md. K. Rehman (2016, March). "An efficient algorithm for detecting traffic congestion and a framework for smart traffic control systems". 2016 18th International Conference on Advanced Communication Technology (ICACT), pp. 802-806.

https://doi.org/:10.1109/ICACT.2016.7423566

10. A. Joshi, D. Mishra (2015, July). Review of traffic density analysis techniques. International Journal of Advanced Research in Computer and Communication Engineering (IJARCCE) [Online]. 4, pp. 209-213, Available: https://doi.org/:10.17148/IJARCCE.2015.4748

11. H-Al-Walid, N. Anjum, U. Tubba, L. Akter, Z Asfad. (2015, June). Traffic density measurement using image processing: An SVM approach. International Journal of Innovative Research in Computer and Communication Engineering (IJIRCCE) [Online]. 3, pp.4979-4986, Available: https://doi.org/:10.15680/ijircce.2015.0306002

12. D. Gangadhar, P. Kumar, A. Mittal. (2012, July). Robust segmentation of moving vehicles under complex outdoor conditions. IEEE Trans. Intell. Transp. Syst. [Online]. 13, pp. 1738-1752. Available: https://doi.org/:10.1109/TITS.2012.2206076

13. P. Khanke, P.S. Kulkarni. (2014). A technique on road traffic analysis using image processing. International Journal of Engineering Research \& Technology (IJERT), 3, pp. 2769-2772.

14. Kavita, R. Saroha, R. Bala, S. Siwach (2013). Review paper on overview of image processing and image segmentation. International Journal of Research in Computer Applications and Robotics (IJRCAR). 1, 1-13.

15. R. C. Gonzalez, R. E. Woods, Digital image processing, Third Edition, Upper Saddle River, New Jersey: Pearson Education Inc., 2008.

16. K.A. Manjula. (2015, May-June). Role of image segmentation in digital image processing for information processing. International Journal of Computer Science Trends and Technology [Online]. 3, pp. 312-318. available:

http://www.ijcstjournal.org/volume-3/issue-3/IJCST-V3I3P52.pdf

17. G. Palubinskas, F. Kurz, P. Reinartz (2008, July). Detection of traffic congestion in optical remote sensing imagery", in Geoscience and Remote Sensing Symposium (IGARSS 2008). IEEE International. Volume 2, pp. 426-429. Available: https://doi.org/:10.1109/IGARSS.2008.4779019

18. A. Mittal, A Monnet, N. Paragios. (2009, January). Scene modeling and change detection in dynamic scenes: A subspace approach. Comput. Vis. Image Underst. [Online] 113(1), pp. 63-79. Available: https://doi.org/:10.1016/j.cviu.2008.07.004

19. S. Gupte, O. Masoud, R. F. K. Martin, N. P. Papanikolopoulos. (2002, March). Detection and classification of vehicles. IEEE Trans. Intell. Transp. Syst. [Online] 3(1), pp. 37-47. Available: https://doi.org/:10.1109/6979.994794

20. Y.G.A. Rao, N.S. Kumar, H.S. Amaresh, H.V. Chirag (2015, November) "Real-time Speed Estimation of Vehicles from Uncalibrated View-Independent Traffic Cameras" in 2015 IEEE Region 10 Conference (TENCON 2015). Available: https://doi.org/ 10.1109/TENCON.2015.7373162

21. O. Barnich, M. V. Droogenbroeck (2010, December).ViBe: A universal background subtraction algorithm for video sequences, IEEE Trans. Image Process. [Online] 20, pp. 1709-1724 Available: https://doi.org/10.1109/TIP.2010.2101613

22. N. Friedman, S. Russell (1997, August) "Image Segmentation in Video Sequences: A Probabilistic Approach". [Online]. Proceedings of the Thirteenth Conference on Uncertainty in Artificial Intelligence (UAI'97), pp. 175-181. Available:

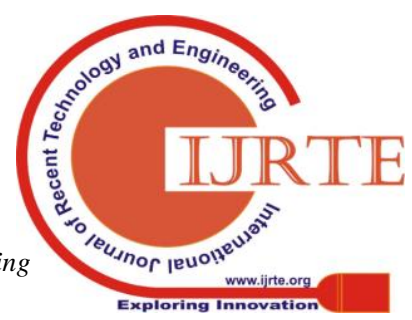


http://dl.acm.org/citation.cfm?id=2074226.2074247

23. S. Javed, Thierry Bouwmans, Andrews Sobra, S. K. Jung. (2015,April). "OR-PCA with dynamic feature selection for robust background subtraction". Proceedings of the 30th Annual ACM Symposium on Applied Computing-SAC'15, [Online]. pp. 86-91. Available: https://doi.org/10.1145/2695664.2695863

24. RA Hadi, G Sulong, LE George (2014, August). An innovative vehicle detection approach based on background subtraction and morphological binary operations methods. Life Sci. J. [Online] 11(8), pp. 230-238. Available: ff7b82ff1ca8c06819f3153c6700da69d812.pdf

25. T. Kasetkasem, P. K. Varshney (2002, August). An image change detection algorithm based on markov random field models. IEEE Trans. Geosci. Remote Sens. [Online] 40(8), pp. 263-1823 Available: https://doi.org/10.1109/TGRS.2002.802498

26. J. W. Hsieh, S. H. Yu, Y. S. Chen, W. F. Hu. (2006, June). Automatic traffic surveillance system for vehicle tracking and classification. IEEE Trans. Intell. Transp. Syst. [Online] 7(2), pp. 175-187. Available: https://doi.org/10.1109/TITS.2006.874722

27. T. Kumar, D. S. Kushwaha (2016, August). "An efficient approach for detection and speed estimation of moving vehicles" Twelfth International Multi-Conference on Information Processing-2016 (ICISP 2016), Procedia Comput. Sci., [Online] 89, pp. $726-731$. Available: https://doi.org/ 10.1016/j.procs.2016.06.045

28. Md. M. Hasan, G. Saha, A. Hoque and Md. B. Majumder (2014, July) "Smart Traffic Control System with Application of Image Processing Techniques", 3rd International Conference on Informatics, Electronics \& Vision 2014, (ICIEV), pp1-4. Available: https://doi.org/ 10.1109/ICIEV.2014.6850751

29. S. S. Kanoji (2012, march-April) Real time traffic light - control and congestion avoidance system", International Journal of Engineering Research and Applications(IJERA), 2(2),.925-929, 2012.

30. R. Velazquez-Pupo, A. Sierra-Romero, D. Torres-Roman, Y. V. Shkvarko, J. Santiago-Paz, D. Gómez-Gutiérrez, D. Robles-Valdez, F. Hermosillo-Reynoso, M. Romero-Delgado (2018, January). Vehicle detection with occlusion handling, tracking, and OC-SVM classification: A high performance vision-based system. Sensors [Online], 18(2), pp. 374-397. Available: https://doi.org/ 10.3390/s18020374

31. G.S. Khekare, A.V. Sakhare (2013, March), "A smart city framework for intelligent traffic system using VANET. 2013 International Multi-Conference on Automation, Computing, Communication, Control and Compressed Sensing (iMac4s), pp. 302-305. https://doi.org/10.1109/iMac4s.2013.6526427

32. S. Badura, A. Lieskovsky (2010, August), "Intelligent Traffic System Cooperation of MANET and Image Processing," First International Conference on Integrated Intelligent Computing (ICIIC 2010), pp. 119-123. https://doi.org/10.1109/ICIIC.2010.41

33. M. Arora, V.K. Bagga (2012, April). "Real Time Traffic Light Control System Using Morphological Edge Detection and Fuzzy Logic" 2nd International Conference on Electrical, Electronics and Civil Engineering (ICEECE'2012).

34. Y-L Chen, B-F Wu, H-Y Huang, C-J Fan (2010, July). A real-time vision system for nighttime vehicle detection and traffic surveillance. IEEE Trans. Ind. Electron.[Online]. 58, pp. 2030-2044. Available: https://doi.org/10.1109/TIE.2010.2055771

35. P. Niksaz (2012, December). Automatic Traffic Estimation Using Image Processing, International Journal of Signal Processing, Image Processing and Pattern Recognition [Online] 5(4),pp 167-174. Available: http://article.nadiapub.com/IJSIP/vol5_no4/13.pdf

36. A. Ambardekar, M. Nicolescu, G. Bebis, M. Nicolescu (2014, June). Vehicle classification framework: a comparative study. EURASIP Journal on Image and Video Processing [Online]. 29(1), pp. 29-42. Available: https://doi.org/10.1186/1687-5281-2014-29

37. S. Sivaraman, M. M. Trivedi (2013, October), "A Review of Recent Developments in Vision-Based Vehicle Detection," 2013 IEEE Intelligent Vehicles Symposium (IV), pp 310-315.Available: https://doi.org/10.1109/IVS.2013.6629487

38. R. P. Avery, Y. Wang, G. S. Rutherford (2004, July) "Length-based vehicle classification using images from uncalibrated video cameras", University of Washington [Online]. pp. 1-6. Available: http://faculty.washington.edu/yinhai/wangpublication_files/ ITSC_05_VC.pdf.

39. M. Pancharatnam, D. U. J. Sonnadara. (2008) "Vehicle Counting and Classification from a Traffic Scene," Proceedings of the 26th National IT Conference, Colombo, Sri Lanka.
40. G.H. Zhang, R. P. Avery, Y.H. Wang (2007, January). A Video-based vehicle detection and classification system for real-time traffic data collection using uncalibrated video cameras, Transportation Research Record [Online], 1993(1), pp.138-147. Available: https://doi.org/10.3141/1993-19

41. N. Buch, J. Orwell, S. A. Velastin. (2008, July). "Detection and Classification of Vehicles for Urban Traffic Scenes". International Conference on Visual Information Engineering VIE08 [Online] pp. 182-187. Available: https://doi.org/10.1049/cp:20080305

42. I. Erhan. (2011, June). Measuring traffic flow and classifying vehicle types: a surveillance video based approach.Turkish Journal of Electrical Engineering and Computer Science [Online] 19 (4), pp. 607-620. Available: https://doi.org/10.3906/elk-0910-266

43. U. Nagaraj, J. Rathod, P. Patil, S. Thakur, U. Sharma (2013,March-April). Traffic jam detection using image processing. International Journal of Engineering Research and Applications(IJERA)[online] 3(2), pp. 1087-1091. Available: http://citeseerx.ist.psu.edu/viewdoc/download?doi=10.1.1.450.4151\& rep=rep $1 \&$ type $=$ pdf

44. V. Dangi, A. Parab, K. Pawar, S.S. Rathod (2012, January) "Image processing based intelligent traffic controller", Undergraduate Academic Research Journal (UARJ), 1, 1-17.

45. A. Kanungo, A. Sharma, C. Singla (2014, March). "Smart Traffic Lights Switching and Traffic Density Calculation using Video Processing", Proceeding of 2014 Recent Advances in Engineering and Computational Sciences (2014 RAECS). pp. 390-395. Available: https://doi.org/ 10.1109/RAECS.2014.6799542

46. J.I. Engel, J. Martín, R. Barco (2017, May). A low-complexity vision-based system for real-time traffic monitoring. IEEE Trans. Intell. Transp. Syst. [Online] 18(5), pp. 1279-1288. Availaable: https://doi.org/ 10.1109/TITS.2016.2603069

47 B.J. Huang, J.W. Hsieh, C.M. Tsai (2017, April). "Vehicle Detection in Hsuehshan Tunnel using Background Subtraction and Deep Belief Network". Intelligent Information and Database Systems: Proceedings 9th Asian Conference on Intelligent Information and Database Systems Part II, pp. 217-226. Available: https://doi.org/10.1007/978-3-319-54430-4_21

48 K. Nellore, G.P. Hancke (2016, November). Traffic management for emergency vehicle priority based on visual sensing. Sensors [Online]. 16(11), pp. 1892-1914. Available: https://doi.org/10.3390/s16111892).

49. S.K. Kumaran, S. Mohapatra, D.P. Dogra, P.P. Roy, B.-G Kim (2019, May). Computer vision-guided intelligent traffic signaling for isolated intersections. Expert Syst Appl. [Online]. 134, pp. 267-278. Available: https://doi:10.1016/j.eswa.2019.05.049).

50. Y. Tang, C. Zhang, R. Gu, P. Li, B. Yang. (2017, February). Vehicle detection and recognition for intelligent traffic surveillance system. Multimedia Tools Appl.[Online]. 76(4), pp. 5817-5832. Available: https://doi.org/10.1007/s11042-015-2520-X

\section{AUTHORS PROFILE}

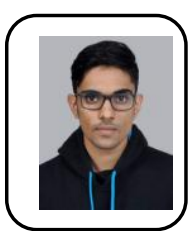

Ishaan Gulati is B.Tech. in Computer Science Engineering from SRM Institute of Technology \& Science and currently working as Associate Software Developer at West Agile Labs. His major interest are software development, image processing. He is a member of the Institute of Engineering and Technology.

R. Srinivasan is M.E. in Computer Science and Engineering and currently working as Assistant Professor at the Computer Science Engineering Department at SRM Institute of Technology \& Science. His interests are Natural Language Processing and Machine Learning. He is a member of the Institute of Engineering and Technology. 